\title{
IMPACT ASSESSMENT OF THE COVID-19 ON TRADE BETWEEN EASTERN EUROPE AND CHINA
}

\author{
Nikolay Megits \\ Webster University, St. Louis, MO, USA \\ Inna Neskorodieva \\ V. N. Karazin Kharkiv National University, Kharkiv, Ukraine \\ Julian Schuster \\ Webster University, St. Louis, MO, USA
}

\begin{abstract}
The high-risk of the rapidly spreading COVID-19 virus worldwide created a necessity for developing a diagnostic tool designed to predict economic development, considering the risks of spreading the coronavirus epidemic. In the proposed research, China is selected strategically due to the U.S. "Buy American" trade policy. Also, the European Union presents various trade barriers for products manufactured in countries of Eastern Europe. The risk-versus-economic efficiency study is performed based on Fibonacci law utilizing trade-dynamic indicators with incorporating the SIR-model used to predict the dynamics of COVID-19 cases in the region. The research was performed based on data collected for the period of March-July 2020. As a result, a scientific model to predict the dynamics of trade volume between China and ten selected Eastern European countries is developed. The results obtained have a practical application and can be used for government institutions and economic agencies to determine their nation's short- and long-term international trade strategy.
\end{abstract}

Keywords: Eastern Europe, China, international trade, COVID-19, epidemic

DOI: http://dx.doi.org/10.15549/jeecar.v7i3.579

\section{INTRODUCTION}

China is the biggest trade partner of Eastern European countries, and the volume of trade operations is rising every year. Russia considers China as its number one strategic trade partner as "Russia and China are reluctant partners and are together only because they have specific trade needs from each other at this moment in history" (Megits, 2016, p. 4). But the spreading of the general pandemic COVID-19 has caused significant changes in the volume and structure of trade between countries. Countries have been forced to implement remedies against the threats of the virus spreading domestically. This situation primarily limits seaports' operations, railways, and complicates foreign trade operations in the world and between China and the countries of Eastern Europe, particularly (OECD, 2020a). 
For this reason, global trade is expected to fall by between $13 \%$ and $32 \%$ in 2020 as the COVID19 pandemic disrupts normal economic activity and life around the world (WTO, 2020a). According to the World Trade Organization, in the second quarter of 2020, the goods trade barometer hit a record low, and global merchandise trade registered a historic fall as the coronavirus pandemic raged (84.5 was down 18.6 points down from the same period yearago) (WTO, 2020b). The countries of Eastern Europe are no exception. In general, according to the latest reports, WTO estimates that the volume of merchandise in world trade in 2020 would shrink by $13 \%$ compared to 2019 (WTO, 2020b). The average share of international trade in GDP in Eastern Europe fluctuates within more than $60 \%$ (Trend Economy, 2020). Because of the disruption in global value chains, the IMF forecasts all East Asia and Pacific economies to contract in 2020. Belarus and Ukraine would be particularly affected, with their economies expected to downsize by $5 \%$ and $7 \%$ by the end of the year, respectively (OECD, 2020b). For example, Russia is losing more than 1 billion rubles per day due to decreased trade with China (Amur Info, 2020).

As uncertainty remains elevated, in terms of economic and trade policy and how the medical crisis will evolve, forecasts of a decline in economic development may be more pessimistic (WTO, 2020b). Because China is one of the Eastern European region countries' main trading partners, and the trade tensions continue to dominate the global trade environment, managing supply chain disruption is a challenge for both regions. It requires a risk-versuseconomic efficiency calculation on the part of every country. This research aims to develop a methodological approach to carry out a predictive assessment to develop the international trade turnover between countries in the context of an acute humanitarian crisis in the global economic space.

\section{LITERATURE REVIEW}

There is a fairly large number of peer-reviewed studies considering trade policy about uncertainty risk (Tian et al., 2020; Imbruno, 2020; Song et al., 2019; Zhou, Chen \& Chen, 2019). But most of them relate to considering the uncertainty risk in sociocultural (Imbruno, 2020), political (Tian et al., 2020), and knowledge environments (Song et al., 2019) and their impact on global value chains (Zhou, Chen \& Chen, 2019). However, it should be noted that these studies were based mainly only on identifying the types of risks of uncertainty and their nature of influence (Imbruno, 2020). However, numerous attempts have been made to evaluate (Zhou, Chen \& Chen, 2019; Tian et al., 2020) and predict (Tian et al., 2020). al., 2020; WIIW, 2020) the volumes of world trade, taking into account the uncertainty risks to justify economic development (WIIW, 2020). The current international trade crisis in the world has been caused by the crisis of national health systems due to being unprepared for a global pandemic. And in this sense, it cannot be viewed as a common mismatch between supply and demand, since this causes a discrepancy in society's function. Today, the pandemic of COVID-19 creates a high degree of uncertainty to be predicted even in the short term, for the development of economic processes, in particular international trade, which ensures human livelihoods (WIIW, 2020; E.C., 2020b). It should also be noted that this uncertainty risk has provoked to develop a humanitarian crisis (OCHA, 2020). This requires a non-standard approach, measures, and diagnostic tools for the economic processes both for the part of each country's government in the world and on the part of international global organizations, communities, and human individuals.

The modern research of economic phenomena (what are caused directly by the spreading of viruses) has been dedicated to determining the development trend and economic growth rates either at the level of the country (Evans, Goldstein \& Popova, 2015; Vasiljeva et al., 2020) or at the level of global economic development (Keogh-Brown et al., 2009). Analysis of literary sources has shown the lack of scientific research that would assess the development of a particular sector of the economy in a humanitarian crisis in relation to international trade. It must be noted that due to the urgency of the current situation, the number of studies to predict trends spreading of the COVID-19 is increasing rapidly. However, most of them are focused on diagnosing the duration of the epidemic (Şahin \& Şahin, 2020), the effectiveness 
of social distancing measures (Vaishnav \& Vajpai, 2020), and supply-demand relationships (Nikolopoulos et al., 2020; Vaishnav \& Vajpai, 2020). Scientists have mostly used the exponential explosion model, SIR, and SIS models to assess the pandemic's impact on the global or national economy (Yates, 2020; Chen et al., 2020). Their studies are focusing on assessing the intensity of the impact in the short term as of 2-3 months and are not assessing any of the specific economic development changes. Besides, a well-known fact is that the spreading of an epidemic slows down significantly within a certain period that it is called the saturation threshold (Chen et al., 2020). It means that first, the exponential stage of a pandemic spreading, then the degree and intensity of the epidemic's spreading starts decreasing.

Definitely, any pandemic will influence the economic processes, particularly international trade, as was indicated by Nesteruk (2020). Even an SIR model is a valuable tool to be used to evaluate the dynamics of an epidemic but cannot be used alone. The SIR- and SIS models do not consider a trade account. Therefore, there is a need to develop more accurate and scientific tools to assess and forecast the impact of the COVID-19 pandemic on the economy, particularly to the certain economic sector of international trade.

\section{METHODS AND MATERIALS}

\section{Determination of factors influencing trade}

As a statistical basis, we used the monthly values of the growth rates of the volume of trade between China and the countries of Eastern Europe for the period from 2006 to May 2020:

$C_{C R F}$ - between China and Russia;

$C_{C U}$ - between China and Ukraine;

$C_{C B}$ - between China and Belarus;

$C_{C B I}$ - between China and Bulgaria;

$C_{C H}$ - between China and Hungary;

$C_{C M}$ - between China and Moldova;

$C_{C P}$ - between China and Poland;

$C_{C R}$ - between China and Romania;

$C_{C S}$ - between China and Slovakia;

$C_{C C h}$ - between China and the Czech Republic.
Fourier spectral analysis has been used to identify economic cycles in the dynamics of indicators for the specified period.

The research algorithm involves identifying factors that are decisive in the conditions of the spread of COVID-19 (current situation), assessing the strength and nature of their influence, and forecasting the dynamics of trade between China and listed Eastern European countries in the context of a pandemic. The research started with an evaluation of the hypothesis (H1) - Foreign trade's fundamental factors don't change during the period of growth and crisis. To be able to prove the hypothesis $\mathrm{H} 1$, the primary task was to determine the periods of the crisis in mutual trade between China and specific countries. According to the Fibonacci law, the entire range of values of Fourier indicators was divided into three classes to describe the dynamics of the volumes of mutual trade:

- crisis dynamics $\left[C_{\min } ; C_{1}\right]$, a decrease in the volume of mutual trade between countries;

- growth dynamics $\left(C_{2} ; C_{\max }\right]$, the volume of turnover trade has an upward trend;

- intermediate dynamics $\left(C_{1} ; C_{2}\right]$.

The values of $C_{1}$ and $C_{2}$ were determined by formula 1 :

$$
\left\{\begin{array}{l}
C_{1}=C_{\text {min }}+0.38\left(C_{\text {max }}-C_{\text {min }}\right) \\
C_{2}=C_{\text {min }}+0.62\left(C_{\text {max }}-C_{\text {min }}\right)
\end{array},\right.
$$

where: $C_{\min }, C_{\max }$ - the minimum or maximum the values of the indicators: $C_{C R F}, C_{C U}, C_{C B}, C_{C B}, C_{C H}$, $C_{C M}, C_{C P}, C_{C R}, C_{C S}, C_{C C h}$ for 2006 - May 2020.

Significant differences in the level of indicators of the dynamics of the crisis and the dynamics of growth have been determined statistically, using the t-test (Neskorodeva \& Pustovgar, 2015). It has been used to identify factors influencing mutual trade. The intermediate class was not used for calculations in order to ensure significant differences in the level of development of mutual trade between countries.

A list of the most important factors that presumably affect the volume of international trade has been formed based on information from a literature review:

- X1 - index of industrial production of the exporting country 
- X2 - index of industrial production of the importing country

- X3 - GDP index of the exporting country

- X4 - GDP index of the importing country

- X5 - index of the economically active population in the exporting country

- X6 - index of the economically active population of the importing country

- X7 - the unemployment rate of the exporting country, expressed (share)

- X8 - an unemployment rate of the importing country, expressed (share)

- X9 - index of real wages in the exporting country

- X10 - index of real wages in the importing country

- X11 - index of domestic capital investment in the exporting country

- X12 - index of domestic capital investments in the importing country

- X13 - foreign direct investment index in the exporting country

- X14 - foreign direct investment index in the importing country

- X15 - index of capital expenditures of the state budget in the exporting country

- X16 - index of capital expenditures of the state budget in the importing country

- X17 - consumer spending index in the exporting country

- X18 - consumer spending index in the importing country

- X19 - level of production profitability in the exporting country

- X20 - level of production profitability in the importing country

- X21 - the level of devaluation of the national currency of the exporting country

- X22 - level of devaluation of the national currency of the importing country
- X23 - average value of the growth rate of world prices for the main goods of trade relations between China and Eastern Europe (Investing, 2020)

- X24 - customs duty on exported products (shares)

- X25 - customs duty on imported products (shares)

- X26 - average value of the growth rates of the total volume of freight transportations of the trading partner countries.

The proposed list of indicators characterized: demand (indicators: X2, X4, X17, X18) and supply in the country (indicators: X1, X3, X19, $\mathrm{X} 20$ ); the presence of production factors (indicators X5-X16), except natural resources due to their stability in the short and mediumterm; the presence of trade barriers between countries (indicators X24, X25); developed logistics (indicator X26); price factors (indicators $\mathrm{X} 21-\mathrm{X} 23$ ). Using the relative values of indicators X1-X26 (indices, shares) has made it possible to bring the indicators to one dimension and improve the modeling results' accuracy.

Factors influencing the dynamics of mutual trade between China and Eastern Europe (level of strength and nature of this influence in the context of the COVID-19 pandemic) have been modeled by using neural networks. The advantages of this method provide higher accuracy of the simulation results in comparison with the methods of linear, nonlinear regression, VAR-model. Higher accuracy is due to the use of a combination of different types of functions for converting an input signal into an output signal in the construction of neural networks. It can be either linear, logarithmic, power, step, sigmoid, or hyperbolic tangent function (Jin et al., 2020). However, linear, nonlinear regression and the VAR model do not involve a combination of different functions. These advantages led to the use of neural networks in this study.

Taking into account the selected type and modeled indicators, the model looked like:

$$
\begin{aligned}
& C=f\left(h^{(j)}\right) \\
& C=\left\{C_{C R F} ; C_{C U} ; C_{C B} ; C_{C B l} ; C_{C H} ; C_{C M} ; C_{C P} ; C_{C R} ; C_{C S} ; C_{C C h}\right\},
\end{aligned}
$$


where $h^{(j)}$ was the output pulse of the j-th layer of neurons - the result of the transformation of the values of independent factors $\left(X_{i}\right)$ into an output pulse, taking into account the weights of the synapse and noise;

$$
X_{i}=\{X 1 ; X 2 ; \ldots X 26\}
$$

Output pulse function:

$$
h^{(j)}=f\left(W^{(k-1)} \cdot H^{(k-1)}+B^{(k-1)}\right),
$$

where $W$ - the vector of weights of the neural network synapses;

$H$ - the vector of output pulses;

$B$ - the noise vector.

The criterion determines the model parameters:

$$
\frac{1}{2} \sum_{k=1}^{n}\left(y_{k}-p_{k}\right)^{2} \rightarrow 0,
$$

where $y_{k}$ - the value of the $k$-th output of the neural network;

$p_{k}$ - the target value of the $k$-th output;

$n$ - the number of neurons in the output layer.

For construction forecasting models, two different data sets have been used: 1 st - values of indicators were diagnosed for the period of trade crisis between countries - crisis model, 2nd values of indicators for the period of the foreign trade growth - growth model. A crisis model was used for forecasting, which can be explained by the economy's crisis during the general COVID19 pandemic and included dependent variables of the models: $C_{C R F}, C_{C U}, C_{C B}, C_{C B}, C_{C H}, C_{C M}, C_{C P}, C_{C R}, C_{C S}$, $C_{C C h}$, and independent: $X 1-X 26$ during the crisis period. In addition, it consists of 283 observations for the crisis model and 292 for the growth model.

Forecasting the volume of trade between China and the countries of Eastern Europe

In order to study the effect of the rate of incidence of the disease across countries, neural networks of the influence of the rate of increase in the incidence (indicator $Z$ ) on indicators $X 1$, $X 2, X 17, \quad x 18, X 23-X 26$, which have a fundamental impact on the dynamics of trade between China and Eastern Europe in a pandemic, have been built. These indicators have a fundamental impact on trade dynamics between China and Eastern Europe in a pandemic. The model had the form: $X_{i}=f(Z)$, $X_{i}=\{X 1 ; X 2 ; X 17 ; X 18 ; X 23 ; X 24 ; X 25 ; X 26\}$. In these models, the indicator $Z$ was an independent variable; $X 1, X 2, X 17, X 18, X 23-X 26$ were dependent. The significant influence of indicators $X 1, X 2, X 17, X 18, X 23-X 26$ on the state of trade was determined using the Granger test (Table 2).

The $\mathrm{Z}$ score for a pair of trading partners has been defined as the rate of increase in the number of diseases in two trading countries. The time range to identify the nature to influence the independent variable on the dependent was selected January-May 2020 (monthly details). The number of observations, taking into account the countries that formed the research sample, is 50 objects. The SIR model was used to predict the $\mathrm{Z}$ score. According to the patterns spreading epidemics (Chen et al., 2020), the exponential growth stage in the number of cases is replaced by a logarithmic one, in which the growth rate of cases is lower than at the exponential stage. Therefore, for this study's purposes, the SIR model was used to determine the duration of the exponential growth period:

$$
t=\frac{1}{\beta} \ln \left[\frac{0.95-0.95 i_{0}}{0.05 i_{0}}\right]
$$

where $t$ - the saturation threshold, which corresponds to the end of the exponential stage spreading the pandemic (months);

$\beta$ - rate of spreading of the pandemic (monthly growth rate of the number of cases);

$\mathrm{i}_{0}$ - initial infection - part of the infected from the country's total population for the 1st month at the moment of detection of the 1 st infected.

\section{RESULT}

The spectral analysis has been performed using the Statistica 12.0 software. The obtained result indicated the absence of statistically significant 
cycles in the dynamics of the indicators of the volume of trade between China and Eastern European countries for the period between 2006 and May 2020. Indicators "Periodogram" and "Density" were statistically insignificant at a significance level of $\mathrm{p}=0.05$ (Table 1 ).

Table 1. Spectral analysis of the growth rates of the trade volume between China and countries of Eastern Europe for 2006 - May 2020

\begin{tabular}{|c|c|c|c|c|c|c|c|c|c|c|c|c|c|c|c|c|c|c|c|}
\hline 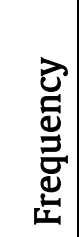 & 苞 & 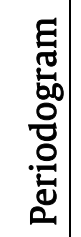 & 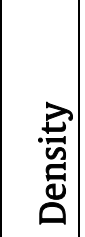 & 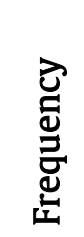 & 苞 & 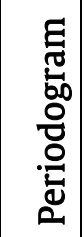 & 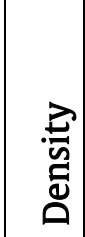 & 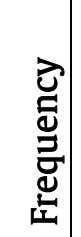 & 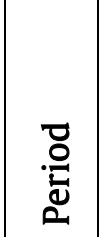 & 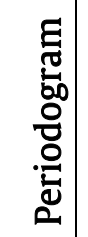 & 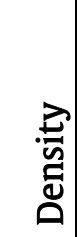 & 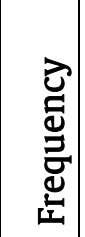 & 苞 & 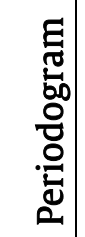 & 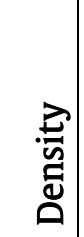 & 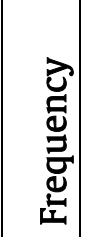 & 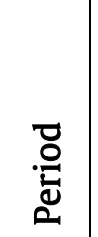 & 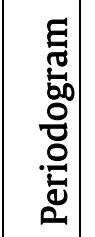 & 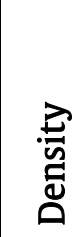 \\
\hline \multicolumn{4}{|c|}{ China-Russia } & \multicolumn{4}{|c|}{ China-Ukraine } & \multicolumn{4}{|c|}{ China-Belarus } & \multicolumn{4}{|c|}{ China-Bulgaria } & \multicolumn{4}{|c|}{ China-Hungary } \\
\hline 0.00 & & 0.00 & \begin{tabular}{|l|}
0.38 \\
\end{tabular} & 0.00 & & 0.00 & 0.04 & 0.00 & & 0.00 & 0.44 & 0.00 & & 0.00 & \begin{tabular}{|l|}
0.32 \\
\end{tabular} & 0.00 & & 0.00 & 0.22 \\
\hline 0.01 & 170.00 & 0.38 & $\mid 0.87$ & 0.01 & 170.0 & 0.01 & $\mid 0.02$ & 0.01 & 170.0 & 0.77 & 0.61 & 0.01 & 170.0 & 0.32 & 0.76 & 0.01 & 170.0 & 0.45 & 0.24 \\
\hline 0.01 & 85.00 & 0.01 & 0.07 & 0.01 & 85.00 & 0.00 & 0.02 & 0.01 & 85.00 & 0.97 & 0.75 & 0.01 & 85.00 & 0.01 & $\mid 0.03$ & 0.01 & 85.00 & $|0.04|$ & 0.25 \\
\hline 0.02 & 56.67 & 0.01 & 0.02 & 0.02 & 56.67 & 0.05 & 0.04 & 0.02 & 56.67 & 0.29 & 0.86 & \begin{tabular}{|l|}
0.02 \\
\end{tabular} & 56.67 & 0.05 & 0.03 & 0.02 & 56.67 & \begin{tabular}{|l|}
0.54 \\
\end{tabular} & 0.50 \\
\hline 0.02 & 42.50 & 0.02 & 0.01 & 0.02 & 42.50 & 0.06 & 0.04 & 0.02 & 42.50 & 0.03 & 0.07 & 0.02 & 42.50 & 0.52 & 0.76 & \begin{tabular}{|l|}
0.02 \\
\end{tabular} & 42.50 & 0.85 & 0.71 \\
\hline 0.03 & 34.00 & 0.40 & 0.93 & 0.03 & 34.00 & 0.92 & 0.76 & 0.03 & 34.00 & 0.23 & 0.16 & $\mid 0.03$ & 34.00 & 0.78 & 0.62 & 0.03 & 34.00 & 0.79 & 0.66 \\
\hline 0.04 & 28.33 & 0.13 & 0.31 & 0.04 & 28.33 & 0.23 & 0.39 & 0.04 & 28.33 & 0.14 & 0.28 & \begin{tabular}{|l|}
0.04 \\
\end{tabular} & 28.33 & 0.24 & 0.74 & 0.04 & 28.33 & \begin{tabular}{|l|}
0.29 \\
\end{tabular} & 0.40 \\
\hline 0.04 & 24.29 & 0.21 & $\mid 0.14$ & 0.04 & 24.29 & \begin{tabular}{|l|}
0.09 \\
\end{tabular} & 0.18 & 0.04 & 24.29 & 0.55 & 0.53 & \begin{tabular}{|l|}
0.04 \\
\end{tabular} & 24.29 & 0.00 & 0.09 & \begin{tabular}{|l|}
0.04 \\
\end{tabular} & 24.29 & 0.20 & 0.23 \\
\hline 0.05 & 21.25 & 0.00 & 0.07 & 0.05 & 21.25 & 0.18 & 0.16 & 0.05 & 21.25 & 0.91 & 0.69 & 0.05 & 21.25 & 0.28 & 0.16 & 0.05 & 21.25 & 0.11 & 0.20 \\
\hline 0.05 & 18.89 & 0.03 & 0.08 & 0.05 & 18.89 & 0.18 & 0.18 & 0.05 & 18.89 & 0.54 & 0.58 & \begin{tabular}{|l|}
0.05 \\
\end{tabular} & 18.89 & 0.54 & 0.99 & 0.05 & 18.89 & 0.40 & 0.22 \\
\hline 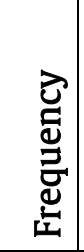 & 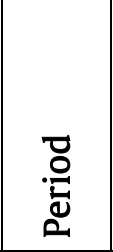 & 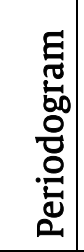 & $\begin{array}{l}\stackrel{\vec{n}}{\bar{n}} \\
\stackrel{\bar{\Delta}}{\Delta} \\
\end{array}$ & 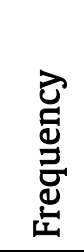 & 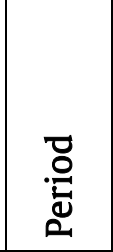 & 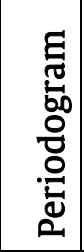 & 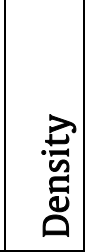 & 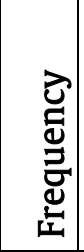 & 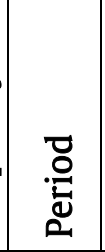 & 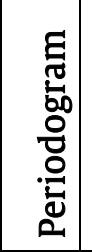 & 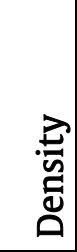 & 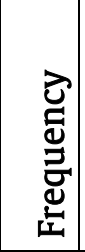 & 苞 & 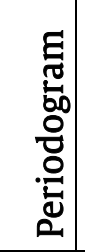 & 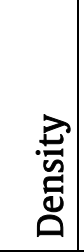 & 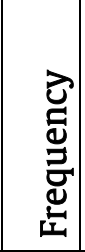 & 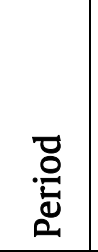 & 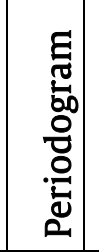 & 党 \\
\hline \multicolumn{4}{|c|}{ China-Moldavia } & \multicolumn{4}{|c|}{ China-Poland } & \multicolumn{4}{|c|}{ China-Romania } & \multicolumn{4}{|c|}{ China-Slovakia } & \multicolumn{4}{|c|}{ China-Czech Rep } \\
\hline 0.00 & & 0.00 & 0.28 & 0.00 & & 0.00 & 0.29 & 0.00 & & 0.00 & 0.18 & 0.00 & & 0.00 & 0.06 & 0.00 & & 0.00 & 0.55 \\
\hline 0.01 & 170.00 & 0.41 & 0.59 & 0.01 & 170.00 & 0.56 & 0.36 & 0.01 & 170.0 & 0.30 & 0.28 & 0.01 & 170.0 & 0.08 & 0.06 & 0.01 & 170.0 & 0.00 & 0.01 \\
\hline 0.01 & 85.00 & 0.07 & 0.05 & 0.01 & 85.00 & 0.36 & 0.36 & 0.01 & 85.00 & 0.51 & 0.37 & 0.01 & 85.00 & 0.03 & 0.10 & 0.01 & 85.00 & 0.01 & 0.95 \\
\hline 0.02 & 56.67 & 0.06 & 0.04 & 0.02 & 56.67 & 0.19 & 0.33 & 0.02 & 56.67 & 0.27 & 0.34 & 0.02 & 56.67 & 0.25 & 0.17 & 0.02 & 56.67 & 0.05 & 0.06 \\
\hline 0.02 & 42.50 & 0.00 & 0.02 & 0.02 & 42.50 & 0.54 & 0.33 & 0.02 & 42.50 & 0.29 & 0.36 & 0.02 & 42.50 & 0.16 & 0.20 & 0.02 & 42.50 & 0.05 & 0.06 \\
\hline 0.03 & 34.00 & 0.23 & 0.62 & 0.03 & 34.00 & 0.06 & 0.23 & 0.03 & 34.00 & 0.56 & 0.50 & 0.03 & 34.00 & 0.17 & 0.29 & 0.03 & 34.00 & 0.09 & 0.08 \\
\hline 0.04 & 28.33 & 63 & 0.40 & 0.04 & 28.33 & 0.25 & 0.17 & 0.04 & 28.33 & 0.52 & 0.69 & 0.04 & 28.33 & 0.48 & 0.99 & 0.04 & 28.33 & 0.56 & 0.72 \\
\hline 0.04 & 4.29 & 0.02 & 0.30 & 0.04 & 24.29 & 0.06 & 0.15 & 0.04 & 24.29 & 0.01 & 0.02 & 0.04 & 24.29 & 0.19 & 0.40 & 0.04 & 24.29 & 0.20 & 0.29 \\
\hline 0.05 & .25 & 0.52 & 0.32 & 0.05 & .25 & 0.22 & 0.14 & 0.05 & 21.25 & 0.62 & 0.62 & 0.05 & 21.25 & 0.37 & 0.35 & 0.05 & 21.25 & 0.06 & 0.17 \\
\hline 0.05 & 18.89 & 0.23 & 0.25 & 0.05 & 18.89 & 0.05 & 0.10 & 0.05 & 18.89 & 0.11 & 0.27 & 0.05 & 18.89 & 0.46 & 0.35 & 0.05 & 18.89 & 0.24 & 0.25 \\
\hline
\end{tabular}

The influence of cycles did not cause the dynamics of indicators. The changes in these indicators were not structural for January-May 2020. 
Using the Fibonacci law, we have determined 3 classes of mutual trade dynamics between China and selected countries. The crisis' dynamics corresponded to the growth rates' values up to 0.91 inclusive, the intermediate dynamics $(0.91 ; 1.36]$, the growth dynamics - over 1.36. Thus, within the research framework, a decrease in trade volume by $9 \%$ or more was considered a crisis. In our case, an increase in trade volume was higher than 36\% (Appendix A).

During the crisis, the period associated with a decrease in mutual trade volume was observed in relations with China in all Eastern European countries for 11.2008-01.2010. As indicated in tables in Appendix A. Russia was the first to react to the global financial crisis, which began from 11.2008. For all other countries, the crises began from 01.2009 and lasted until 10.2009. For Ukraine, Belarus, Hungary, Romania, this decline continued until 12.2009. Individual crises were observed in Russia during 2015-2016, Ukraine 2013-2015, Belarus - 2012, 2015-2016, Bulgaria - 2015-2016, Hungary - 2015, Moldova - 2015. Romania - 2012, Slovakia - 2012, 2014-2015, Czech Republic - 2012-2013. During JanuaryMay 2020, China's trade with Russia decreased (the volume of trade in dollar terms decreased by
$5.09 \%$ compared to the period January-May 2019), Ukraine (by 1.31\%), Belarus (by $12.50 \%$ ), Bulgaria (by 1.47\%), Hungary (by 28.64\%), Moldova (by 5.36\%). Trade with Poland, Romania, Slovakia, and the Czech Republic for JanuaryMay 2020 was increased due to the not so high growth rates of the proportion of the infected population combined with a more stable economy.

Deviation in the level of values of the growth rates of trade volumes for the class of crisis and growth were statistically significant. The statistical significance of the differences was confirmed by the $t$-test $-2.74(\mathrm{df}=573, \mathrm{p}=0.05)$. The developed models made it possible to identify the factors to influence the dynamics of the volume of mutual trade between countries.

The fundamental factors (that have a significant impact on the volume of trade between China and the countries of Eastern Europe) have been determined by indicators $X 1$, $X 2, X 17, X 18, X 23-X 25$. Using the Granger test made it possible to prove the influence of these variables on the dynamics of trade volume between China and Eastern Europe (C) and to determine the time lag of the response of trade between nations. The result is shown in Table 2 .

Table 2. Causality of economic factors and trade between China and the countries of Eastern Europe

\begin{tabular}{|c|c|c|c|c|}
\hline \multirow{2}{*}{ Direction of causation } & \multicolumn{2}{|c|}{ Crisis model } & \multicolumn{2}{c|}{ Growth model } \\
\cline { 2 - 5 } & Time lag, months & Prob. & Time lag, months & Prob. \\
\hline$X 1 \rightarrow C$ & $L=2$ & 0.0011 & $L=2$ & 0.0110 \\
\hline$X 2 \rightarrow C$ & $L=2$ & 0.0046 & $L=2$ & 0.0029 \\
\hline$X 17 \rightarrow C$ & $L=1$ & 0.0061 & $L=1$ & 0.0095 \\
\hline$X 18 \rightarrow C$ & $L=1$ & 0.0007 & $L=1$ & 0.0012 \\
\hline$X 23 \rightarrow C$ & $L=0$ & 0.0033 & $L=0$ & 0.0170 \\
\hline$X 24 \rightarrow C$ & $L=0$ & 0.0018 & $L=0$ & 0.0083 \\
\hline$X 25 \rightarrow C$ & $L=0$ & 0.0164 & $L=0$ & 0.0027 \\
\hline
\end{tabular}

The estimation procedure, implemented in the EViews 10 program, involved testing the hypothesis that indicators $X 1, X 2, X 17, X 18$, and $X 23-X 25$ (separately) did not significantly affect the dynamics of indicator $C$ in the absence and presence of a lag (L) at 1-6 months. To evaluate this hypothesis, a vector of the autoregression model was used. The indicator $C$ was considered as a dependent variable, and the independent variables were the lags of the indicators $X 1, X 2$, $X 17, X 18, X 23-X 25$.

Table 2 lists only significant causal relationships. In this case, the time lags indicated in the table correspond to the lag (of the possible $L=0-6)$, at which the value of the Prob was the minimum for each causal relationship. The indicator Prob assessed the statistical significance of the influence of the indicators the probability of accepting the hypothesis of the 
insignificance of the cause-and-effect relationship. The relationship is significant when the value of the indicator Prob. $<0.05$.

Granger's test showed that the most influential of independent variables appear after a certain time lag, which corresponded to 1 month for indicators $X 17-X 18$. For the $X 1-X 2$ indicator - 2 months and without a lag, international trade reacted to the dynamics of the $X 23-X 25$ indicators.

The influence of indicators $X 1(-2), X 2(-2), X 17$ $(-1), X 18(-1), X 23-X 25$ on the dynamics of trade was significant for both models: the model of the dynamics of the crisis and the dynamics of growth (Table 3 ).

Table 3. Characteristics models of the dynamics of trade between China and Eastern Europe for 2006 May 2020

\begin{tabular}{|l|c|c|c|c|}
\hline \multicolumn{1}{|c|}{ Model type } & $\begin{array}{c}\text { Neural network } \\
\text { hierarchy }\end{array}$ & $\begin{array}{c}\text { Training } \\
\text { error }\end{array}$ & Test error & $\begin{array}{c}\text { Validation } \\
\text { error }\end{array}$ \\
\hline Crisis dynamics model & MLP 7-8-4-1 & 0.0004 & 0.002 & 0.006 \\
\hline Growth dynamics model & MLP 7-6-3-1 & 0.0009 & 0.001 & 0.001 \\
\hline
\end{tabular}

Dynamics models of trade between China and the countries of Eastern Europe (characteristics were presented in table 3) were built in Statistic 12.0 with the regression function's implementation. The dependent variable of the models was the indicator $C$; the independent ones were the indicators $X 1(-2), X 2(-2), X 17(-1)$, $X 18(-1), X 23-X 25$. To construct the models, we used the backpropagation algorithm. The hierarchy of the neural network and the values of the neuron's weights have been determined with the goal to minimize the deviation of the target values of the dependent variables from the actual output values. The models identified the minimum of the error functions and the minimum values of training, test, and validation error (Table 3).

The time of the spread of COVID-19, referred to as the crisis dynamics of foreign trade, specified a decrease in the volume of trade for Russia, Ukraine, Belarus, Bulgaria, Hungary, and Moldova. For other Eastern European countries, the pandemic period characterized intermediate dynamics of the volume of trade with China. But their inclusion allowed us to build a model for forecasting the volume of trade during the period not only of crisis but also of growth, which determines its versatility and great practicality. This model makes it possible to assess the positive and negative contribution of factors (their values and dynamics) to the possibility of developing trade between Eastern Europe and China.

The analysis deviations allowed calculating indicators of $C_{C R F}, C_{C U}, C_{C B}, C_{C B}, C_{C H}, C_{C M}, C_{C P}, C_{C R}, C_{C S}, C_{C C h}$, that have been obtained by using the crisis model. Results showed that from 2006 to 2019, the percentage deviation varies in the range of 0.4-2.9\%; for January-May 2020, it ranges from $3.9-4.7 \%$. Therefore, unaccounted for factors of influence were determined using the correlation coefficients $C_{C R F}, C_{C U}, C_{C B}, C_{C B}, C_{C H}, C_{C M}, C_{C P}, C_{C R}, C_{C S}, C_{C C h}$ for the 1st data set. Also, factors that were presumably influencing international trade in a pandemic (indicators $X 1-X 26$ ) for the 2 nd data set for January-May 2020. This indicator was the average value of the growth rates of the total freight transport volumes of trading partner countries (indicator $X 26$ ), for which the value of the correlation coefficient was +0.81 . The $X 26$ indicator's inclusion with a lag of $\mathrm{L}=0$ in the crisis dynamics model reduced the percentage deviation up to a maximum of $2.8 \%$. It means that during the COVID-19 pandemic, $X 26$ is a specific factor affecting trade volume between China and Eastern Europe. This factor's significance was due to freight traffic limitations between China and Eastern European countries during the quarantine period (Table 4). Indicators of training, test, and control errors of models did not exceed 0.0023 , which indicated the models' adequacy. 
Table 4. Characteristics of model indicators errors influencing the growth rate of the number of COVID-19 cases on the foreign trade

\begin{tabular}{|c|c|c|c|c|}
\hline \multirow{2}{*}{$\begin{array}{l}\text { Dependent } \\
\text { variable }\end{array}$} & \multirow[b]{2}{*}{ Model } & \multicolumn{3}{|c|}{ Adequacy indicators } \\
\hline & & Training error & Test error & $\begin{array}{c}\text { Validation } \\
\text { error }\end{array}$ \\
\hline$X 1$ & MLP 1-4-1 & 0.0034 & 0.0014 & 0.0016 \\
\hline$X 2$ & MLP 1-7-1 & 0.0011 & 0.0010 & 0.0010 \\
\hline$X 17$ & MLP 1-2-4-1 & 0.0013 & 0.0009 & 0.0008 \\
\hline$X 18$ & MLP 1-3-1 & 0.0008 & 0.0006 & 0.0007 \\
\hline$x 23$ & MLP 1-3-3-1 & 0.0015 & 0.0008 & 0.0009 \\
\hline$x 24$ & MLP 1-4-2-1 & 0.0020 & 0.0016 & 0.0011 \\
\hline$x 25$ & MLP 1-3-4-1 & 0.0023 & 0.0014 & 0.0012 \\
\hline$x 26$ & MLP 1-5-1 & 0.0015 & 0.0011 & 0.0008 \\
\hline
\end{tabular}

At the time of the research, most Eastern European countries (except Belarus and Hungary) were at the stage of exponential growth in the number of COVID-19 infections. The exponential growth parameters, according to the SIR model, are presented in Table 5.

Table 5. Pandemic spread: Parameters of the exponential growth of the infection rate in Eastern Europe

\begin{tabular}{|c|c|c|c|}
\hline Country & Initial infection rate $\left(\boldsymbol{i}_{\mathbf{0}}\right)$ & Pandemic spreading $(\boldsymbol{\beta})$ & $\begin{array}{c}\text { Saturation } \\
\text { threshold, months }(\boldsymbol{t})\end{array}$ \\
\hline Russia & $1.6173 \mathrm{E}-05$ & 1.99 & 7.03 \\
\hline Ukraine & $1.53929 \mathrm{E}-05$ & 1.90 & 7.38 \\
\hline Belarus & $1.61471 \mathrm{E}-05$ & 2.10 & 6.64 \\
\hline Bulgaria & $5.12854 \mathrm{E}-05$ & 1.98 & 6.48 \\
\hline Hungary & $5.03428 \mathrm{E}-05$ & 1.22 & 10.49 \\
\hline Moldova & $9.95488 \mathrm{E}-05$ & 1.85 & 6.57 \\
\hline Poland & $6.08638 \mathrm{E}-05$ & 1.53 & 8.29 \\
\hline Romania & $1.15662 \mathrm{E}-04$ & 1.61 & 7.47 \\
\hline Slovakia & $6.66055 \mathrm{E}-05$ & 1.37 & 9.14 \\
\hline Czech Republic & $2.81784 \mathrm{E}-04$ & 1.29 & 8.60 \\
\hline
\end{tabular}

The initial infection rate is defined as the ratio of the number of cases in March 2020 to countries' populations. The spreading rate was determined using trend lines plotted with the time series of the number of infected peoples during March-July 2020 (Knoema, 2020). The rate of spreading corresponded to the average daily growth rate of the number of cases in the countries during the period of exponential growth (the coefficient of approximation of the trend lines was 0.88-0.94). 
Using parameters of $i_{0}, \beta$ (formula 5 ), the saturation threshold has been calculated, corresponding to the number of months from the beginning epidemic in the country to the incidence's peak. The number of cases was described by a logarithmic trend line with a constant decrease in the monthly increase period. Accordingly, the saturation threshold for Russia was predicted to reach at 02.10.2020, Ukraine - at 12.10, Bulgaria - at 14.09, Moldova at 17.09, Poland - at 09.11, Romania - at 15.10, Slovakia - at 04.12, the Czech Republic - at 18.11. For Belarus and Hungary, even though they have passed an exponential stage based on statistical data, the saturation threshold has also been calculated. For Belarus, it was predicted for September 19, 2020, Hungary - January 6, 2021. In the calculations for these countries, growth rates during exponential growth were used as the $\beta$ indicator. The "unfinished" stage of exponential growth indicates the possibility of a repeated increase in the number of infections (the second wave of infection).

The saturation threshold has been used to calculate the $Z$ indicator and forecast trade development for the end of 2020. At the moment of saturation, based on average growth rates, the number of infected people would be: for Russia 3,389,648 people, Ukraine - 328,970 people, Belarus - 228,939 people, Bulgaria - 32,128 people, Hungary - 13,422 people, Moldova 64,974 people, Poland - 185,113 people, Romania - 164,990 people, Slovakia - 8,438 people, Czech Republic - 41,452 people.

The value of the $Z$ index for the period from June 2020 to the saturation period would be: for Russia - 4.04, Ukraine - 4.61, Belarus - 3.38, Bulgaria - 2.75, Hungary - 2.98, Moldova - 2.63, Poland - 4.05, Romania - 3.24, Slovakia - 3.68, Czech Republic - 2.50. After the saturation threshold, the $Z$ index, as a destabilizing factor in international trade development, was not calculated because the increase in the number of infected people during this period was insignificant. Also, as the experience of China showed, after the saturation threshold, the economy must begin to recover, and trade to expand (Trend Economy, 2020).

The predicted impact of the COVID-19 pandemic on China's trade for 2020 is shown in Figure 1.

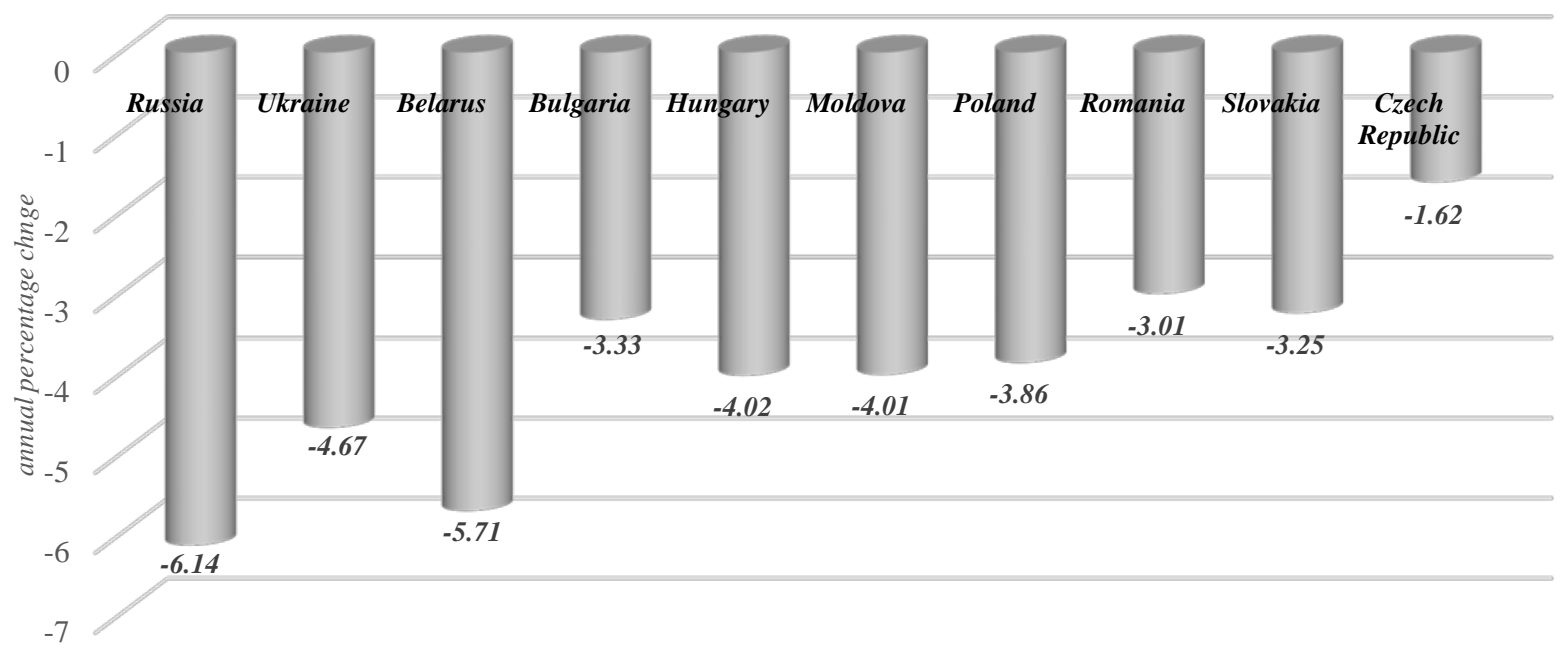

Figure 1. Forecasted change in the trade volume China and Eastern Europe in 2020 with influencing of the COVID-19 pandemic

\section{DISCUSSION AND CONCLUSION}

Within this study's framework, the research was based on a methodological approach. It allowed us to make a prospective assessment toward developing foreign trade turnover between China and the countries of Eastern Europe as a strategic trading partnership, taking into account the risk of uncertainty. It is 
important to note that obtained results allow providing an adequate and accurate forecast, which can act as a preventive, diagnostic tool and contribute to developing an international trade strategy for a specific country or entire region. Utilizing the developed method would allow avoiding additional economic losses and, to a certain extent, leveling the risk of uncertainty. Unlike other predictive models of foreign trade (Zhou, Chen \& Chen, 2019; Tian et al., 2020), these models take into account the conditions of a high level of uncertainty (the intensity spreading the COVID-19 virus and the associated forced restrictions on economic activity). Besides, it would allow us to perform forecast of the level of turnover based on the integral account of foreign trade factors, as well as predict its volumes while taking into account the situation with the spreading of the epidemic.

Even more, in contrast to the SIR- and SIS models (Yates, 2020; Chen et al., 2020), the proposed study allows government agencies to interpret the impact of pandemic health issues on economic processes. As discussed by The Economist (2020), the growth of China's influence on Eastern European countries' economies is highly predictable. China already has a big presence in the region through foreign direct investments. And today, we are already seeing that China is one of the few countries that are recording stronger growth. It indicates that the Chinese economy would recover much faster compared to Western economies. Thus, we are seeing China expanding its economic influence over the region, either through investment all through loans from Chinese lenders to Russia, countries of Central Asia, the South Caucasus, and all over the Western Balkans.

According to the obtained forecast due to the impact of COVID-19 on the economy (a decrease in production, falling prices on world markets, a reduction in freight transport, etc.) at the end of 2020, the volume of mutual trade between China and the selected countries of Eastern Europe would be decreased by $1.62 \%-6.14 \%$. The highest percentage of decline would be for Russia 6.14\%. This can be explained by the Russian highest rate of increase in COVID-19 cases among Eastern European countries multiplied by an unfavorable price environment in the global oil and gas markets. In addition, the economic decline reduces the export potential and the need for imported goods, which has an additional destabilizing effect on Russia's foreign trade. Nevertheless, a significant reduction in foreign trade operations with China would reflect on Belarus (-5.71\%) and Ukraine (-4.67\%). This can be explained by the fact that during the past five years, the average volume of a share of trade with China was Russia's 5.73\% GDP, in Ukraine's GDP - 7.62\%, in Belarus's GDP - 6\% (WIIW, 2020; WTO, 2020a; OECD, 2020b). Considering this, the predicted decrease in the trade volume with China, as a result of the impact of the COVID-19 pandemic at the end of 2020, would lead to a decrease in GDP by $0.35 \%$ for Russia, $0.36 \%$ for Ukraine, and $0.34 \%$ for Belarus. In general, the decline of trade share in GDP in Eastern Europe would amount to $0.27 \%$ based on our forecast, taking into account the current humanitarian crisis reflecting a decrease in trade with China. Also, due to stagnated Eastern European internal and external markets, development does not imply increasing in trade volumes, product quality improvement, or expansion of product range. It necessitates the introduction of an innovation strategy to ensure competitiveness in trade activities.

The performed research and obtained results are based on foreign trade data between China and selected Eastern European countries. Therefore, they are relevant only to these specific countries but represent a much wide spectrum of the region. It is important to note that the forecast of changes in trade volumes was carried out until the end of 2020 due to the high level of uncertainty in the development of the COVID-19, which limits the possibility of obtaining reliable medium and long-term forecasts of foreign trade turnover between countries.

\section{REFERENCES}

Amur Info. (2020). Russia is losing 1 bill rubles per day due to coronavirus in China (Article in Russian). Retrieved from https://www.amur.info/news/2020/02/21/1 68292

Chen, Y.-C., Lu, P.-E., Chang, C.-S., \& Liu, T.-H. (2020). A Time-dependent SIR model for COVID-19 with Undetectable Infected Persons. Retrieved from https://arxiv.org/abs/2003.00122. 
E.C. (2020b). The impact of the COVID-19 pandemic on global and E.U. trade.

Retrieved from https://trade.ec.europa.eu/doclib/docs/2020 /april/tradoc_158713.pdf

E.U. (2020). Commission Implementing Regulation (E.U.) 2020/426 of March 19 2020, amending Implementing Regulation (E.U.) 2020/402 making the exportation of certain products subject to the production of an export authorization.

Evans, D. K., Goldstein, M., \& Popova, A. (2015). The Next Wave of Deaths from Ebola? The Impact of Health Care Worker Mortality. Policy Research working paper, no. WPS 7344. Washington, DC: World Bank Group.

Imbruno, M. (2020). Importing under trade policy uncertainty: Evidence from China. Journal of Comparative Economics, 47(4), 806-826.

Investing. (2020). Котировки фьючерсов в реальном времени. Retrieved from https://ru.investing.com/commodities/realtime-futures.

Jin, P., Lu, L., Tang, Y., \& Karniadakis, G.E. (2020). Quantifying the generalization error in deep learning in terms of data distribution and neural network smoothness. Neural Networks, 130, 85-99.

Keogh-Brown, M., Wren-Lewis, S., Edmunds, W. J., Beutels, P., \& Smith, R. D. (2009). The possible macroeconomic impact on the U.K. of an influenza pandemic. Health Economics, 19(11), 1345-1360.

Knoema. (2020). Global Markets Moved by coronavirus Outbreak. Retrieved from https://knoema.com/lwdhxyc/globalmarkets-moved-by-china-coronavirusoutbreak.

Megits, N. (2016). The Impact of Russia-China Trade Relationship on the U.S. Economy. Journal of Eastern European and Central Asian Research, 3(2), 12. Obtained from: DOI: https://doi.org/10.15549/jeecar.v3i2.135

Neskorodeva, I.I., \& Pustovgar, S.A. (2015). An Approach to Predicting the Insolvency of Ukrainian Steel Enterprises Based on Financial Potential. Journal of Eastern European and Central Asian Research, 2(2),
33-43. Obtained from: DOI: https://doi.org/10.15549/jeecar.v2i2.104

Nesteruk, I. (2020). Statistics-Based Predictions of Coronavirus Epidemic Spreading in Mainland China. Innov Biosyst Bioeng, 4(1), 13-18. Nikolopoulos, K., Punia, S., Schäfers, A., Tsinopoulos, C., \& Vasilakis, C. (2020). Forecasting and planning during a pandemic: COVID-19 growth rates, supply chain disruptions, and governmental decisions. European Journal of Operational Research. DOI: 10.1016/j.ejor.2020.08.001.

OCHA. (2020). COVID-19 Notes on Humanitarian Crises - An ICMHD Health Policy Contribution. Retrieved from https://reliefweb.int/report/world/COVID19-notes-humanitarian-crises-icmhdhealth-policy-contribution

OECD. (2020a). Tackling coronavirus (COVID-19) Contributing to a global effort. Retrieved from http://www.oecd.org/coronavirus/en/

OECD. (2020b). COVID-19 crisis response in Eastern Partner countries. Retrieved from https://www.oecd.org/coronavirus/policyresponses/COVID-19-crisis-response-in-eueastern-partner-countries-7759afa3/

Şahin, U., \& Şahin, T. (2020). Forecasting the cumulative number of confirmed cases of COVID-19 in Italy, U.K. and USA using fractional nonlinear grey Bernoulli model. Chaos, Solitons \& Fractals, 138, 109948.

Song, M-L., Cao, S.-P., \& Wang, S.-H. (2019). The impact of knowledge trade on sustainable development and environment-biased technical progress. Technological Forecasting and Social Change, 144(C), 512523.

The Economist (August 2020). Video presentation: COVID-19: The road ahead for eastern Europe, Retrieved from https://economist.zoom.us/rec/play/vMUvd uH8pzw3EtSStASDA6R6W9XreK2sgCce8qY MmR3nBijXYAevYrUTMLaLInOLr65w2tSuVk VliZ5W?startTime=1597917927000\&_X_zm _rtaid=D5Ay_Mb9R2aSOamOY2HYA.1598969136108.03de3f0b b39d1e023876ce6eb5a516bc\&_x_zm_rhtaid $=520$ 
Tian, J., Sim, N., Yan, W., \& Li, Y. (2020). Trade uncertainty, income, and democracy. Economic Modelling, 90, 21-31.

Trend Economy. (2020). Trade Data Insights. Retrieved from https://trendeconomy.ru/trade

Vaishnav, V., \& Vajpai, J. (2020). Assessment of impact of relaxation in lockdown and forecast of preparation for combating COVID-19 pandemic in India using Group Method of Data Handling. Chaos, Solitons \& Fractals, 140, 110191.

Vasiljeva, M., Neskorodieva, I., Ponkratov, V., Kuznetsov, N., Ivlev, V., Ivleva, M., Maramygin, M., \& Zekiy, A. (2020). A Predictive Model for Assessing the Impact of the COVID-19 Pandemic on the Economies of Some Eastern European Countries. Journal of Open Innovation: Technology, Market, and Complexity, 6(3), 92. DOI: $10.3390 /$ joitmc6030092

WIIW. (2020). Eastern Europe Coronavirus tracker: Preparing for the worst. Retrieved from https://wiiw.ac.at/eastern-europecoronavirus-tracker-preparing-for-theworst-n-430.html

WTO. (2020a). Trade set to plunge as COVID-19 pandemic upends global economy.
Retrieved from

https://www.wto.org/english/news_e/pres2 0_e/pr855_e.htm

WTO. (2020b). Goods barometer confirms steep drop in trade but hints at nascent recovery. Retrieved from https://www.wto.org/english/news_e/news 20_e/wtoi_19aug20_e.htm

WTO. (2020c). Documents for meetings. Retrieved from https://docs.wto.org/dol2fe/Pages/FE_Search /FE_S_S006.aspx?DataSource=Cat\&Query=@ MeetingId $=160705 \&$ Language $=$ English $\&$ Cont ext=ScriptedSearches\&languageUIChanged $=$ true.

Yates, C. (2020). How to model a pandemic. The Conversation. Retrieved from https://theconversation.com/how-tomodel-a-pandemic-134187.

Zhou, Y., Chen, S., \& Chen, M. (2019). Global value chain, regional trade networks and Sino-EU FTA. Structural Change and Economic Dynamics, 50, 26-38. 


\section{Appendix A}

China-Russia

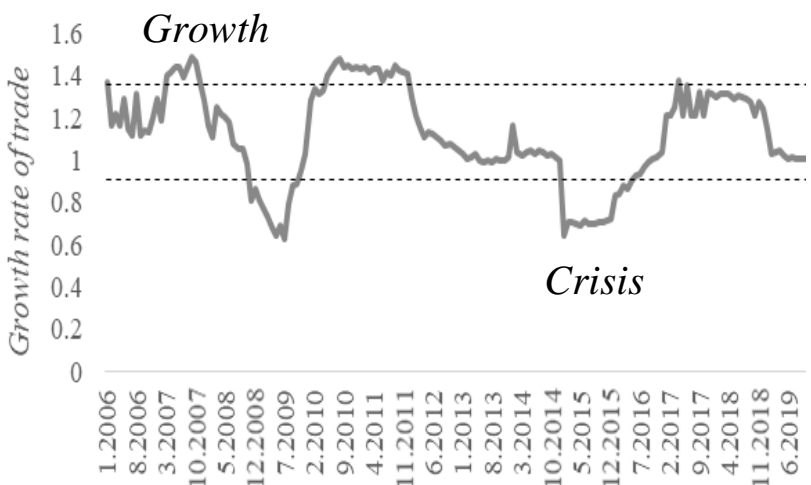

China-Belarus

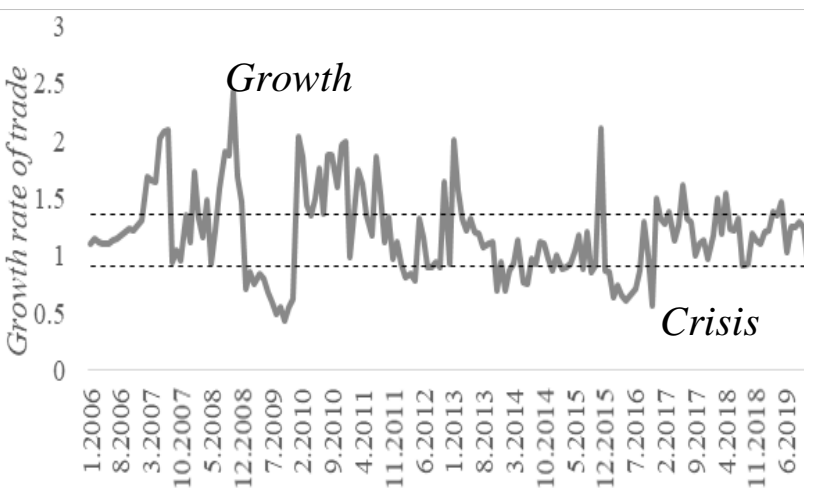

China-Hungary

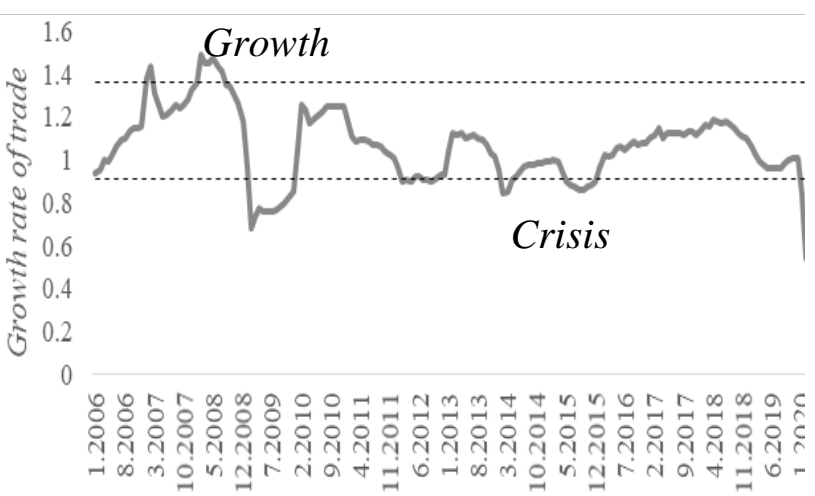

China-Ukraine

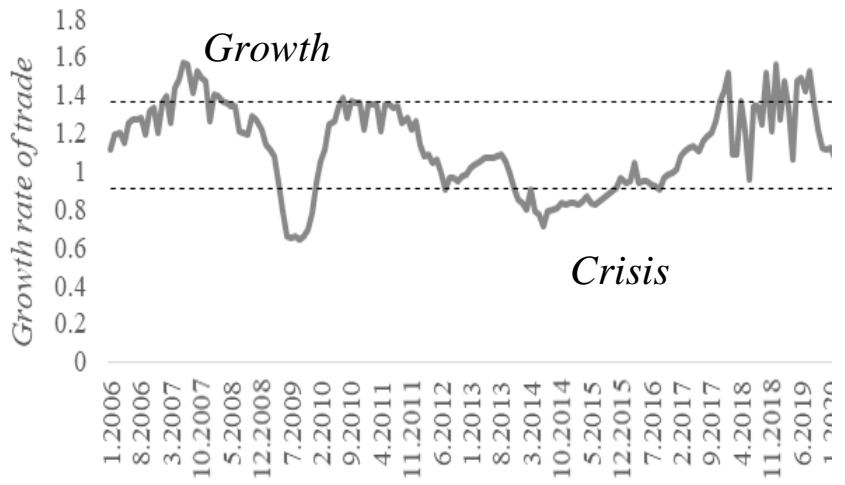

\section{China-Bulgaria}

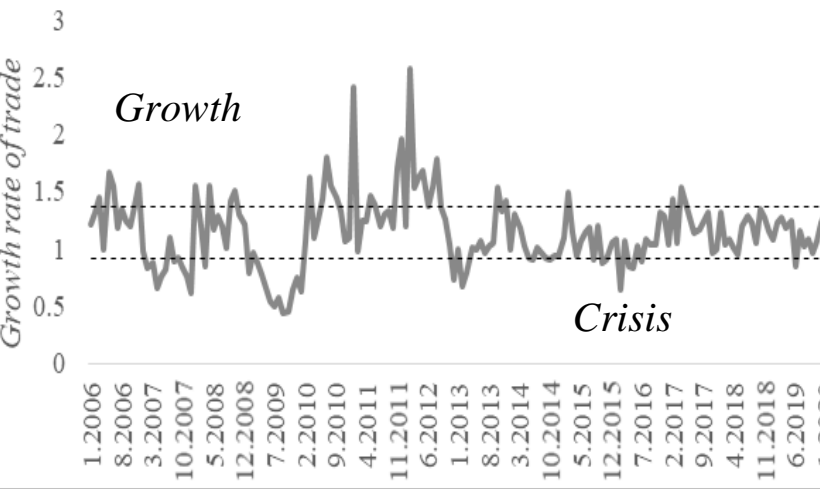

\section{China-Moldova}

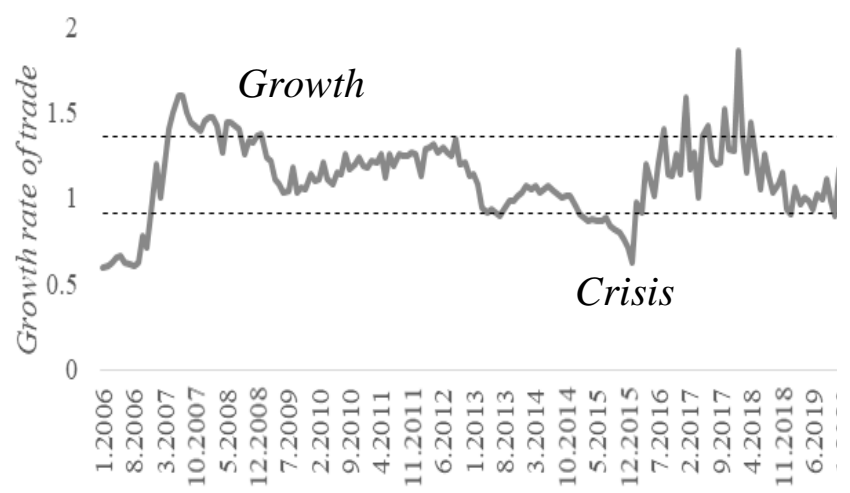


Appendix A: (Continued)

China-Poland

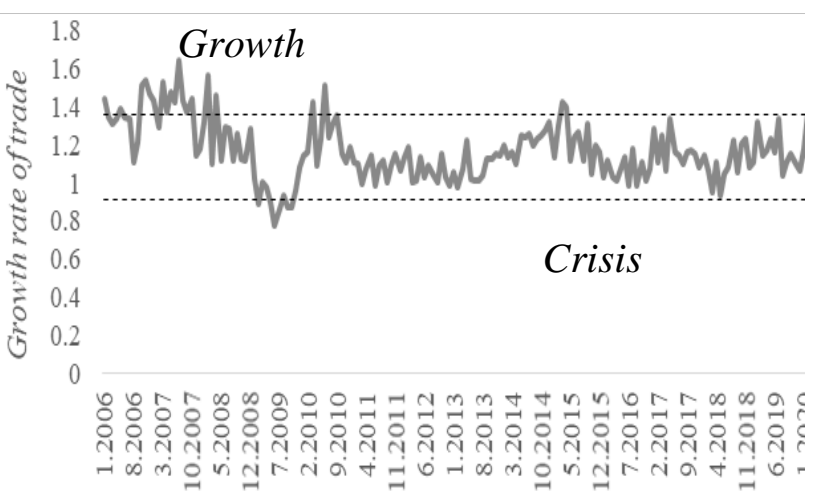

China-Slovakia

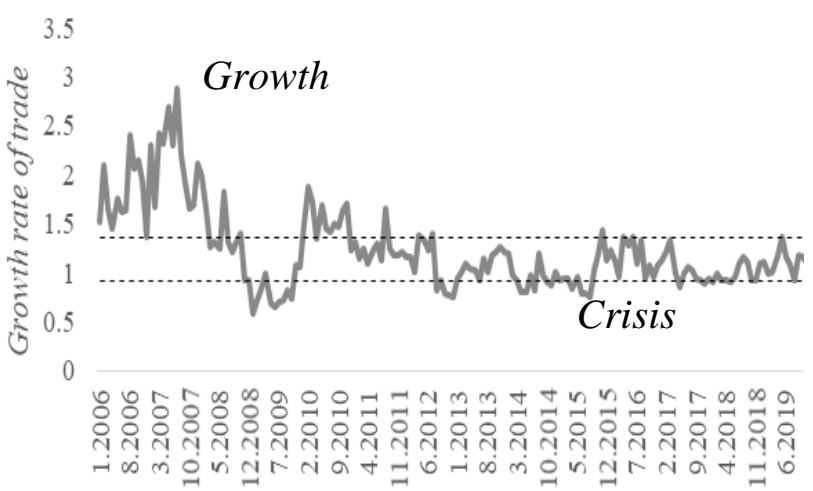

China-Romania

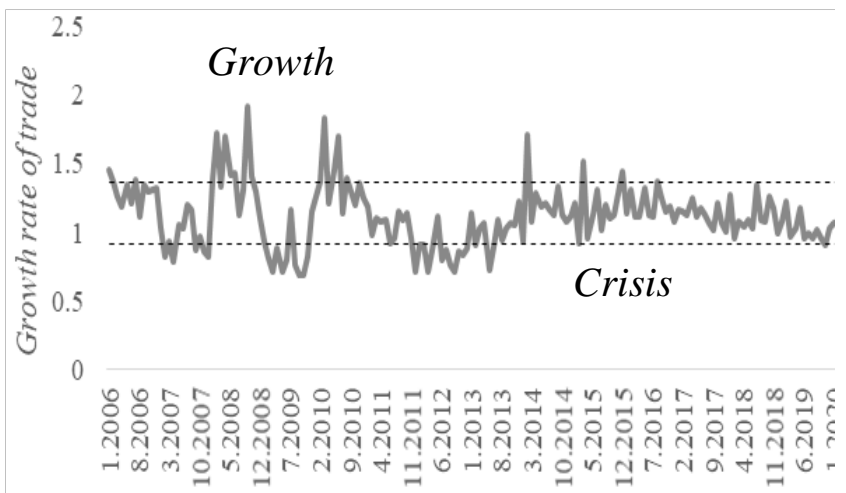

China-Czech Republic

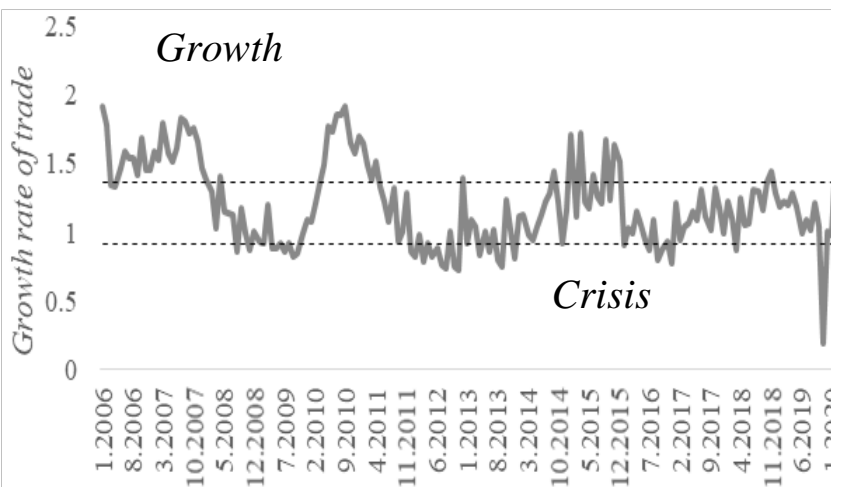

ABOUT THE AUTHORS

Nikolay Megits, email: nikolaymegits45@webster.edu

Dr. Nikolay Megits is the Adjunct Professor at Webster University, St. Louis, MO, USA.

Dr. Inna Neskorodieva is an Associate Professor at Karazin Business School. V. N. Karazin Kharkiv National University, Ukraine.

Dr. Julian Schuster is the President of the Webster University, St. Louis, MO, USA. 